\title{
PRESENCIA GADITANA EN EL SANTO DOMINGO DEL SIGLO XVIII. ASPECTOS CULTURALES: SOCIALES, ECONÓMICOS Y RELIGIOSOS.
}

\author{
María del Mar Barrientos Márquez \\ Universidad de Cádiz
}

El trabajo que nos proponemos llevar a cabo, se centra en el estudio de la vida y muerte de aquellos gaditanos que «cruzando el charco» en el S.XVIII, vienen a morir a Santo Domingo.

Muchos de estos hombres vinculados desde siempre a su compañera inseparable la mar, arriban a aquellas tierras como tripulantes de la Flota de Indias, como comerciantes, o como militares. Fué gente emprendedora y con iniciativa, que se arriesgaron para encontrar una mejor forma de vida que les proporcionase mayores ingresos económicos y un ascenso en el status social.

Lo que nos motivó a escoger éste ámbito, fué el papel que nuestra ciudad Cádiz-desempeñó en la relación con América, desde los primeros momentos del descubrimiento, hasta el final del período colonial, haciendo especial hincapié en el S.XVIII.En este Siglo es cuando Cádiz alcanza su mayor esplendor y protagonismo a raíz del traslado, desde Sevilla, de la Casa de la Contratación (1717), lo que conllevó el desplazamiento del centro de gravedad de la Carrera de Indias a nuestra ciudad.

Por otro lado, la elección del marco dominicano, viene impuesto por el atractivo que éste nos ofrecía, teniendo en cuenta primero que es aquí donde comienza la historia colonial del Nuevo Mundo. Sería el laboratorio dónde se experimentaría el proceso colonizador que se llevaría a cabo en el resto de la América Hispánica. En la Española se marcaría el rumbo de la colonización americana, pues durante los primeros treinta años del S.XVI su capital, Santo Domingo fué «el principal puerto de las Indias y el lugar de llegada y estación de salida de casi todas las expediciones conquistadoras del continente (1). En definitiva, las puertas de las Indias, dónde todo aquel que se dirigiese al Nuevo Mundo entraría en contacto con esta nueva realidad, muy distinta a la Vieja Europa. Y segundo, la naturaleza marítima del Caribe que le confiere una extrema movilidad tanto económica como política y social. El Caribe, fué «nudo estratégico, cruce de ambos mundos, el Nuevo y el Viejo, centro del comercio mundial, en donde se ensayaron $\mathrm{y}$ : desarrollaron diferentes sistemas económicos» (2). Además de que para el S.XVIII Santo Domingo comienza a recobrar el auge que tuvo antaño.

\section{FUENTES}

Para llevar a cabo ésta investigación hemos trabajado con expedientes de Bienes de Difuntos de gaditanos (término en el que incluímos los nacidos tanto 
en la capital como en los pueblos que comprenden la actual provincia de Cádiz) fallecidos en la isla durante el siglo de las Luces.

La documentación consultada procede del Archivo General de Indias de Sevilla, de la Sección de Contratación. Es en esta Sección donde aparecen inventariados la mayor parte de los expedientes de Bienes de Difuntos. También hay documentación en relación a este tema en las Secciones de Escribanía de Cámara, Arribadas, Justicia, Indiferente General y en las distintas Audiencias recogidas del Archivo General de Indias.

Para este trabajo que ahora presentamos, hemos seleccionados seis expedientes de Bienes de Difuntos pertenecientes a indivíduos naturales o vecinos de Cádiz, todos ellos difuntos en Santo Domingo.

Los seis expedientes no nos darán una visión completa de cual era la forma de vida en este grupo de gaditanos que emigran a las nuevas tierras, pero sí, nos mostrarán una imagen global, de quienes eran estos hombres, cuales eran sus inquietudes al marchar para esas tierra, qué buscaban, si se asentaban y radicaban en ellas, si formaban familias, cuales eran sus medios de vida, cuales eran sus creencias, como morían, si llegaron a acumular fortunas, etc.

Los expedientes se comprenden entre los años de 1739 y 1800 $1739,1742,1746,1748,1763$ y 1787 - fechas que vienen a coincidir con acontecimientos significativos de a mediados del S.XVIII. El Caribe de nuevo, se vuelve a convertir en el escenario de las rivalidades europeas (3). Por otro lado, también se produce cierta activación del comercio a comienzo de la década de los cuarenta, el cambio de sistema de navegación en comvoy por el de registros sueltos, o las Leyes de Comercio Libre de 1765.

El número de Autos de gaditanos fallecidos en Santo Domingo que encontramos para el S.XVIII, es relativamente escaso. Suponemos que serían muchos más los gaditanos que visitarían la isla, pero debido a que la mayoría de estos hombres eran militares, comerciantes, etc... cuando se encontraban en precario estado de salud, no se embarcaban en un viaje de envergadura, quedándose en su tierra de origen, por lo que no los encontramos como difuntos en la antigua «Española». Igual sucedería cuando fueran de edad avanzada. Todo ello, creemos que justifica que el número de expedientes no guarde relación con el número real de gaditanos que llegaron a esas tierras dominicanas, que sería mucho mayor. A esto hay que unirle la desconfianza que siempre se tuvo hacia el Juzgado de Bienes de Difuntos, pues no existía seguridad de que éste cumpliera las últimas voluntades de los fallecidos (4). Por lo que en muchas de las ocasiones los que veían próxima su muerte, y se encontraban alejados de sus hogares y parientes cercanos, recurrían a terceros, que de forma encubierta harían llegar la herencia a los familiares en su tierra de origen.

Hay que destacar el valor cualitativo que nos ofrece esta documentación, pues aparecen documentos de la más variada índole. 


\section{LOS BIENES DE DIFUNTOS.}

Fueron muchos los hombres que por distintos motivos emigraron a las ensoñadas tierras del Nuevo Mundo, dejando a sus parientes más queridos en la península. Como estos últimos no se encontraban en el lugar del fallecimiento, al conocerse la sucesión, bien por testamento o abintestato, se crea una institución «El Juzgado de Bienes de Difuntos», encargada de hacer metálico todas las propiedades del difunto y enviarlas a España a la Casa de la Contratación de Cádiz -ubicada en nuestra ciudad desde 1717- donde sus funcionarios se encargarían de buscar a los legítimos herederos para hacerles la entrega. A estos Bienes pertenecientes a peninsulares fallecidos en América, sin herederos conocidos o ausentes, se les llamó Bienes de DIfuntos. Se entiende por Bienes de Difuntos:

«aquella categoría o clase especial de bienes dejados en Indias por españoles o extranjeros que, fallecidos en aquellas remotas regiones, en España o en sus viajes de travesía carecían de herederos residentes en aquellos países, por lo que tras el óbito, surgía la indeterminación de quién o quienes pudieran ser los legítimos sucesores de tales bienes hereditarios, o quién habría de pechar con la vigilancia, conservación y tutela de los mismos hasta su adición por el sucesor» (5).

Por lo tanto, la custodia y cuidado de los Bienes y la determinación de los herederos respondían al fín para el que fué creado el Juzgado de Bienes de Difuntos.

En la transmisión de los Bienes, se distingue dos gestiones distintas, la indiana y la española, donde intervienen dos órganos con actuaciones muy específicas, pero muy bien relacionadas, el Juzgado de Bienes de Difuntos en Indias y la Casa de la Contratación en España.

Para analizar la compleja estructura de la administración de los Bienes de Difuntos, vamos a seguir y a estudiar los Bienes de los gaditanos fallecidos en Santo Domingo a lo largo del S.XVIII. Seguiremos la línea marcada por las obras de Faustino Gutierrez Alviz (6) y Jose $\mathbf{M}^{a}$ Ots Capdequí (7) fundamentadas en la Recopilación de las Leyes de los Reinos de Indias (8).

El mecanismo de la administración de los Bienes de Difuntos se ponía en marcha tras el óbito de una persona en Indias cuyos herederos estaban ausentes.

A partir de este momento intervenían las autoridades indianas. Desde 1550 los Virreyes y los Presidentes de las Audiencias debían nombrar a principio de cada año a un Juez de Difuntos. Este cargo recaería en un oidor de la Audiencia correspondiente. Los lugares donde no hubiese Virrey ni Audiencia, serían los Gobernadores y Oficiales Reales los encargados de nombrar al Juez; si en el 
lugar donde se produciese el fallecimiento no existiese Juez, ni Cabildo, ni Tenedor de Bienes de Difuntos, y si el fallecido era español, se nombraban los denominados «Jueces Habilitados» (9) que acostumbraban ser los Corregidores o Justicias.

Este no sería el caso de Santo Domingo, porque es allí en su capital donde Fernando V, ordena crear la primera Real Audiencia (10) en 1511 -por la Real Provisión dada en Burgos el 5 de octubre-. Esta Audiencia, tendría jurisdicción (11) para todo el continente hasta 1527

«la competencia territorial de la Audiencia se extendería a todas las Villas e lugares de toda la dicha Ysla e Indias e tierra firme del mar Oceano...».

El mandato de los Jueces sería anual y a partir de 1609 bianual (12).

La misión del Juez de Bienes de Difuntos consistía en custodiar los Bienes de los que morían en Indias con o sin testamentos.

El procedimiento más común, era que el Juez se hiciera cargo de los Bienes de Difuntos, disponiendo su conversión en dinero, excepto los metales preciosos ya que estos eran fácil de depositar (13), con el fín de enviarlos a la Casa de la Contratación desde donde se buscaba a los herederos para hacerles la entrega.

Por ello en muchas de las ocasiones los expedientes de Bienes de Difuntos se iniciaban en la Casa de la Contratación, bien por petición de los herederos, o de los funcionarios de la Casa para buscar a dichos herederos. No obstante, en los casos que nos ocupan los seis expedientes se inician en Indias, dos en Santo Domingo capital, los de Thomas Figuera y Joseph Guerrero, por orden del Juez de Bienes de Difuntos D. Antonio de Villa Urrutia, y los cuatro restantes por las autoridades competentes en el lugar donde se produce el fallecimiento; así el auto de Pedro Vazquez se abre en 1746 por el Alcalde Ordinario de Santiago de los Caballeros D. Francisco Linares. También en esta ciudad, pero por el Alcalde Mayor de las Armas y Teniente Coronel Gobernador D. Joseph Bazarte se inicia el expediente de Juan Sanchez en 1756. En la villa de Banica comienza en 1763 el de Francisco Hinostrosa por el Alcalde ordinario D. Pedro Aguilera Blanco y en 1787 en Dajabón el de Joaquin Arizo, por Francisco Pepin, Capitán de Infantería e Inspector General de la Frontera de la Raya de Dajabón.

De los seis expedientes, sólo dos se inician a partir de la apertura del testamento, el de Francisco Hinostrosa y el de Pedro Vazquez. La disposición testamentaria del primero es dictada poco antes a la muerte, Francisco Hinostrosa hace testamento el día 26 de mayo de 1773, dejando este mundo dos días después. Sin embargo, distinto es el caso de Pedro Vazquez que testa varios años antes de morir en diciembre de 1742, falleciendo en 1756. El motivo quizás fuese que al estar dedicado al comercio como intermediario, e incluso llevando escrituras de riesgo, testase tempranamente por si la muerte le sorprendía. 
Hay un auto, el de Josef Guerrero, que se abre a partir de unos apuntes o memoria que dicta ante escribano, momentos antes de fallecer, a mediados de 1739, con la intención de que éste -el escribano- redactase su testamento.

Los tres expedientes restantes corresponden a abintestatos, el de Thomas Figueras, el de Juan Sanchez, y el de Joaquin Arizo, aunque en el caso de este último hay testigos que declaran que el difunto hizo testamento en Santo Domingo capital, pero al no hallarse se le declara abintestato.

Pensamos que el motivo de no dictar testamento podría estar en que la muerte les sorprende sin esperarla, o bien por causa de las edades, pues estos indivíduos son los más jóvenes del grupo aquí estudiado con 30, 40 y 28 años respectivamente

\section{INVENTARIO.}

Una vez sucedido el óbito y comunicado al Juez, se procedía a inventariar todos los Bienes del difunto. Sería el albacea, designado por el testador -si éste aceptaba-el encargado de realizarlo, siempre dando cuenta ante la autoridad competente.

El escribano junto al albacea -si lo había- y testigos pasaban a la casa donde había fallecido el individuo, a muy tardar al día siguiente, y se procedía a hacer el inventario de los Bienes. Solían ser muy escrupulosos, se hacía constar hasta la prenda más deteriorada que tuviese el difunto.

Entre los expedientes trabajados, aparecen dos inventarios que hacemos constar en los apéndices por la significación que ellos tienen, el de Pedro Vazquez (APENDICE I) por la descripción que se hace de las joyas que se hallaron entre sus Bienes, y el de Francisco Hinostrosa (APENDICE II), como muestra de hombre de comercio, poseedor de ropa, joyas, e incluso una goleta, la «Santa Rosa» y libros e instrumentos de pilotaje, etc.

Por otro lado, los inventarios también nos pueden dar información acerca de la situación tanto social como económica de la isla. En nuestro caso encontramos datos sustanciosos acerca de la situación social y precio de los esclavos, o descripción de la ganadería existente.

Francisco Hinostrosa deja entre sus Bienes un negro nombrado Cupidón de 20 años, criollo de Santo Thomé y una negra llamada Dorotea de 13 años de «casta Congo», éste adjetivo era el que se acostumbraba a usar para declarar el origen de los negros africanos (14). También declara tener

«una casa en la isla de Santo Thome en la mediania de la poblacion muy bien acondicionada, a cargo de una esclava llamada Maria al 
cuidado de Don Gerardo Dubento y que en esa casa hay 21 piezas de esclavo» (15).

María, la esclava que tenía Francisco a cargo de la casa, era una sierva doméstica. Estos tipos de esclavo, eran los más favorecidos respecto al trato y la consideración. Gozaron de ventajas que los otros no tuvieron. Su función era la de actuar como doncella, cocinera, limpiar los aposentos,etc...además de ser un signo de prestigio social (16) para sus dueños.

Lo normal era que los esclavos estuviesen trabajando en el campo, bien laboreando las tierras de sus amos, o dedicados al cuidado del ganado en los hatos. En los años que hemos trabajado este tipo de propiedad -hatos de ganadotoma el relevo de las plantaciones en cuanto a importancia económica, debido a que el ciclo del azúcar entra en crisis siendo sustituído por el de la explotación ganadera -el hato-. La relevancia que toma el hato en Santo Domingo, viniendo a ser «el modo de producción colonial del siglo XVIII» (17) es debida, a que a principios de siglo, la parte francesa de la isla -por la Paz de Ryswick en 1697, España reconoce a Francia la ocupación de la parte occidental de Santo Domingo, llamándose a partir de ahora Saint Domingue y más tarde Haitíconstituye una economía de plantación en base al empleo multitudinario de esclavos negros, con parte de una minoría blanca. Desde muy temprano, se crea un cultivo intenso, no posibiltando tierras para la cría de ganado. Ahora bien, la alimentación del esclavo exigía grandes cantidades de carne, así como para su trabajo eran necesarios contar con animales para el movimiento de sus trapiches azucareros. Para cubrir esta necesidad francesa, la colonia española, ofrecía amplias extensiones de tierra despoblada, que incitó a sus habitantes a dedicarse a la cría generalizada de ganado vacuno y caballar. Por ello, a lo largo del siglo XVIII y sobre todo en la segunda mitad, se produce un intercambio entre las colonias, los hateros de la zona española compraban esclavos en la zona francesa, y entregaban a cambio ganado.

Los hatos dominaban la zona este del país, y lo normal era que tuviesen de 200 a 300 cabezas (18).

Un caso representativo de lo dicho anteriormente es el de Melchora Barrado (19), una dominicana que tal como aparece en la documentación pertenece «a una de las familias mas apoderada de la zona». Es suegra de Manuel Romero, albacea que el difunto Francisco Hinostrosa nombró en su testamento. Pues bien, sabemos que Melchora en su disposición testamentaria nombra a su hija, llamada María Dalman y a su yerno Manuel Romero como sus herederos. Les deja varios esclavos, los cuales estaban repartidos en las siguientes propiedades que también les lega:

«tierra en los sitios de Capitanejo -valle de Neyba- y un hato en Matayaya -en la jurisdiccion de Banica-, donde se incluia un bohio, un conuco, treinta bestias caballares, docientas reses vacunas de crianza con un año, veinte y cinco cerdos de crianza y once cabras. Ademas de esto, Manuel Romero y su esposa poseían 
dos caballos padrones de yegua, un rucio tuerto y otro bello, doce yeguas, una de ellas tuerta, quatro potricos de un año, dos vacas paridas, quatro becerros de un año, y dos reses torras».

En la memoria hecha por Joseph Guerrero en 1739 en Santo Domingo también dispone y deja como herencia a su esposa Dominga además de una negra con sus dos hijitos, «un hato con 67 reses vacunas, de ellas 50 enteras y 17 para el multiplico y 4 caballos».

\section{TASACION.}

Una vez inventariados los Bienes, se procedía a su tasación por peritos experimentados

«mandamos que no se puedan vender Bienes de Difuntos sin ser primero tasados por personas peritas y de buena conciencia» (20)

El precio de los esclavos comienza a incrementarse a finales del siglo XVII, llegando su apogeo en el siglo XIX. Presentamos aquí una relación de precios de esclavos en los años que nos ocupan, concretamente en 1750 y 1767 :

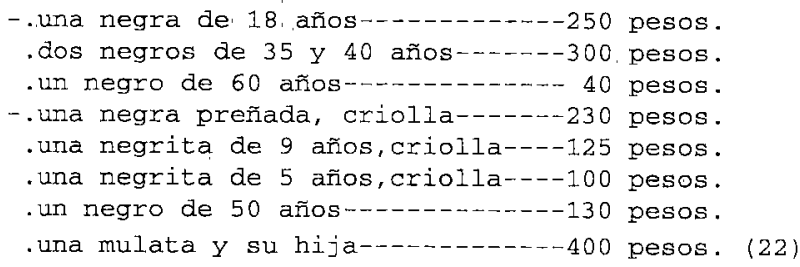

\section{PREGON, ALMONEDA Y REMATE.}

Terminada la tasación de los Bienes del Difunto, se procedía a su venta en pública almoneda. Esta iba antecedida de un pregón.

Los pregones solían ser cantados por pregoneros de profesión o nombrados para la ocasión, al son de «caja y cartel». Casi siempre eran hombres de color. Para tales acontecimientos se elegían como marcos, los lugares más populosos y concurridos de la ciudad -plazas, calles céntricas-, con el fín de que acudieran el mayor número posible de personas para poder participar en los remates de los Bienes. En Santo Domingo capital, todos los bandos a voz de pregonero, tambor y pífano se anunciaban en la Plaza Mayor antes de recorrer las Cuatro Calles. El pregón hecho para vender los Bienes de Joaquin Arizo, se hace en

«las cuatro esquinas de la Plazuela de la ciudad de Santo Domingo por boca del negro Antonio Gurudian al son de caja y gritos» (23). 
Lo normal era que el pregón se hiciera un sólo día, pero había veces que por la cuantiosidad de los bienes o por las muchas posturas hechas sobre algún bien determinado, podía durar varios días. Este es el caso de los 30 pregones que se cantan para vender en pública almoneda una casa que Josef Guerrero le dejó a su esposa, tras su muerte. Las casas estaban situadas en la calle Caño, cerca de las Cuatro esquinas de la Plaza Chica de Santo Domingo. Los pregones comienzan el 23 de setiembre de 1746 y se dan en dias alternos hasta el 3 de noviembre del mismo año. Las posturas son innumerables, y la cotización de la casa va subiendo, hasta que es rematada en el teniente Diego García como mayor postor en la cantidad de 1225 pesos. Su interés por este inmueble se basaba en que poseía la casa inmediata y así lograba aumentar su propiedad.

En las almonedas se remataban todos los Bienes excepto el oro, plata y piedras preciosas, pues éstos eran fáciles de depositar (24). Sin embargo, las joyas que se hallaron entre los bienes de Pedro Vazquez y de Joaquin Arizo, fueron vendidas en publica almoneda en la isla. Las pertenecientes a Pedro salen a subasta en Santiago de los Caballeros, el 18 de febrero de 1743. El motivo que se dá es que en la isla éstas tienen mayor valor. La respuesta podría ser que España de nuevo se encuentra envuelta en una guerra con Inglaterra-Guerra de los Nueve Años (1739-48), y a la hora de hacerlo líquido, alcanzarían mayor valor en Santo Domingo que en España. En el segundo caso, las alhajas que quedan de los Bienes de Joaquin no salen a subasta en Santiago, donde fallece, sino que la subasta se hace en la capital. La explicación que se dá es «por haber allí mayor número de habitantes y mejores postadores» (25).

En las subastas estarían presentes el Juez de Bienes de Difuntos, si existiese en el lugar donde hubiese fallecido el indivíduo, y en su defecto las justicias ordinarias, además de el albacea, testamentarios o tenedor y el defensor si lo hubiese.

Las almonedas, al igual que los pregones, se solían hacer en lugares de gran afluencia de público. Por ejemplo la que se hace para rematar los Bienes de Thomas Figueras, se celebra en la calle Plateros, en la actualidad calle Meriño (26). En el caso de Pedro Vazquez que fallece en Santiago, ésta tiene lugar en la Plaza de la Merced de dicha ciudad.

La almoneda podía durar uno o varios días dependiendo del tiempo que se tardaba en rematar todos los bienes. La que se hace para vender las pertenencias de Joaquin Arizo, comienzan el 1 de marzo de 1787, en Santiago de los Caballeros, dura cuatro días, e incluso el último día siendo domingo, el cura párroco, permite que durante dos horas se proceda a hacerla, dada la escasez de la población, que se veía acrecentada los domingos por la asistencia a misa.

En general, los precios en los que se remataban los bienes, venían a coincidir, casi siempre, con los que se habían fijado en la primera tasación. 
Normalmente, como compradores de los Bienes destacan aquellos individuos relacionados con el ámbito del difunto, compañeros de trabajo, amigos, etc...

\section{LAS CAJAS DE LOS JUZGADOS DE BIENES DE DIFUNTOS.}

En los distritos donde había Audiencia, como es el caso que nos acupa, era un oficial de la Real Hacienda el que se hacía cargo de las Arcas del Juzgado de Bienes de Difuntos. Una Real Cédula dada el 7 de julio de 1578, ordenaba que

«...las cajas de Bienes de Difuntos esten siempre en el aposento donde estuviese la Caja Real o en otra parte de las Casas Reales, en que pueda tener toda seguridad, que a ella se traiga todo lo que hubiere en oro, plata en pasta y moneda y de alli se remita a estos reinos con lo demas de nuestra Real Hacienda, por cuanta aparte».

Las Ordenanzas de la Casa de la Contratación, disponían que hubiera una caja de tres llaves, de las cuales tendría una el Juez, otra el Fiscal de la Audiencia y otra el Escribano de ella, donde se quedaría el dinero, oro, plata y piedras preciosas.

\section{EL ENVIO DE LOS BIENES DE DIFUNTOS A LA PENINSULA.}

Una vez que se habían convertido en metálico, los Bienes serían embarcados en la primera Flota de Indias y enviados a la Casa de la Contratación, que desde 1717 estaba ubicada en Cádiz.

Observamos que en Santo Domingo, en el período comprendido entre 1746 al 1756, el dinero que se enviaba a la Casa de la Contratación, no era el que procedía directamente de la venta de los Bienes de los difuntos que fallecieron en la isla, sino que se gastaba y se libraba posteriormente del situado (27). Como en esos años la situación económica que se vivía en la isla era muy mala, se procuraba solucionarla con cualquier medio, como podía ser el dinero que dejaban como herencia los que morían en la isla. Pero ese dinero había que abonarlo a los herederos. La solución era que del situado que tenía asignado la isla se liberara la partida que correspondía a los herederos del difunto. Los 61 pesos de 128 cuartos, 2 reales de plata y' 32 maravedíes que deja Thomas Figueras, tras fallecer el 26 de enero de 1748 en Santo Domingo se gastan y posteriormente llegan a la Casa de la Contratación, librados del situado

«...en una partida que dirigieron los oficiales reales de la Veracruz que llego a España el 24 de abril de 1750» (28)

o los 2175 pesos de 128 cuartos y 29 maravedíes del gaditano Pedro Vazquez, que arribaron a la península procedentes de 
«...una partida que se practica por medio del libramiento de oficiales reales dirigidos a los Mexico para que desfalquen del situado primero y que debiere venir a este presidio la cantidad de su importe, se certificara lo que quedara de los 771 pesos y se hara saber a los oficiales reales de estas cajas para que aumente dicha cantidad a la que debieren librar de estos caudales a Mexico donde se dirige este tribunal para practicar la remision» (29).

Una vez que los Bienes hubieran llegado a la península, se depositarían en la Casa de la Contratación, que se encargaría de custodiar, administrar y entregar los Bienes de Difuntos a sus legítimos herederos. Así terminan cinco de los autos que hemos trabajado. Y solo uno, el de Francisco Hinostrosa, es declarado «Bienes Vacantes», por la falta de prueba aportadas por sus presuntos herederos. El Fiscal de la Casa de la Contratación ordena «librar carta de pago a favor de la Real Hacienda», correspondiéndole a ésta dos tercios de la herencia y el tercio restante se destina al sufragio por el alma de Francisco.

\section{DURACION DEL PROCESO.}

La duración del proceso, desde el óbito hasta la entrega de la herencia, vendría condicionada por otros muchos factores, tales como que los herederos residieran o no en Cádiz -lugar donde se ubicaba la Casa de la Contratación-y si no residían en Cádiz dependía del período que tardasen las diligencias hechas por los funcionarios de la Casa de la Contratación para localizarlos y de la demostración de la legitimidad de los herederos.

En el caso de nuestros hombres, la duración oscila, la mínima de tres años que transcurren desde que Joaquin Arizo fallece, hasta que sus Bienes le son entregados a su padre en Cádiz,y la máxima los 37 años que tardan los Bienes de Francisco Hinostrosa en declararse vacantes, quizás fuese este el motivo.

\section{¿QUIENES ERAN ESTOS HOMBRES?}

Los seis autos de Bienes de Difuntos que nos encontramos pertenecen a hombres. Solo uno Joaquin Arizo era natural de Cadiz capital, los demás eran naturales o vecinos de la provincia: Thomas Figueras del Puerto de Santa Maria; Juan Sanchez y Pedro Vazquez de Jerez de la Frontera; Joseph Guerrero de la Villa de Rota y Francisco Hinostrosa de Sanlúcar de Barrameda.

Todos son hijos legítimos, lo que conocemos por el expediente, en el que bien aparece el certificado de bautismo o bien la declaración de testigos que los exponen como tales. Algunos formaron parte de familias numerosas: Juan Sanchez cuenta que tenía tres hermanos y que dos de ellos habían muerto, Joseph Guerrero dice ser miembro de una familia de cinco hermanos; y otro Joaquin Arizo habla de un solo hermano. De los otros tres restantes no conocemos la composición familiar. 
A través del conocimiento del entorno familiar, cargos que ocupan, amigos que declaran, etc...hemos llegado al conocimiento de las edades de estos hombres, casi todos eran mayores de 40 años, excepto Joaquin Arizo y Thomas Figueras que contaban con 28 y 30 años respectivamente.

De los seis indivíduos estudiados, 3 de ellos estaban casados, Thomas Figueras, Pedro Vazquez y Joseph Guerrero. El resto, Juan Sanchez, Joaquin Arizo y Francisco Hinostrosa permanecieron solteros.

En cuanto a las ocupaciones de nuestros hombres, nos encontramos con distintas profesiones. Joseph Guerrero cuando muere, ocupa la plaza de sargento, perteneciente a la Compañía de Artillería, destinado en la Raya de Dajabón; también en Dajabón, pero como escribiente del Administrador de Fronteras, estaba ocupando su puesto Joaquin Arizo, que además practicó el comercio a pequeña escala con cordobanes, con el fín de sacar algunas ganancias complementarias. Como hombres dedicados exclusivamente al comercio encontramos entre nuestros expedientes a tres. Juan Sanchez, que llegó a la isla ocupando la plaza de pífano y una vez allí decide crear una pequeña compañía aparcería con otro socio, dedicándose al comercio con pequeñas cantidades de tabaco, telas, encajes, etc...; Pedro Vazquez sin embargo, actúa como intermediario, vendiendo joyas en América, además de llevar firmada una escritura de riesgo, con un vecino de Cádiz. Por el inventario de los Bienes que se realiza de Francisco Hinostrosa tras su fallecimiento, de los papeles hallados como son letras de cambio, recibos, facturas, papeles en distintos idiomas »frances, ingles y dinamarques»-y porque en el expediente aparece nombrado como «hombre de comercio», deducimos que de los tres sujetos es el que practica un comercio a mayor escala y con mayores beneficios. Tenía muchos hombres a su disposición que le servían de intermediarios para vender su mercancia; practicaba el comercio marítimo; uno de los puntos que frecuentaba a menudo era la ciudad de San Fernando de Montecristi, y quizás por su situación fronteriza con la zona francesa de la isla, mantenía buenas relaciones comerciales con sus vecinos. Encajes, todo tipo de telas, velas, harina francesa, bacalao, pimiento, aguardiente, palo de mora, azúcar, etc,...eran algunas de las mercaderías con las que Francisco comerciaba. Thomas Figueras no sabemos a que se dedicó.

El denominador común que poseían estos sujetos, que les indujo a partir hacia las nuevas tierras fué poder alcanzar un mayor status económico y social.

De estos gaditanos que marchan para la Española, sólo tres se pueden considerar como emigrantes que se establecen definitivamente en aquellas tierras. Joseph Guerrero, es quizás el que más se arraiga, porque a los pocos años de llegar destinado a Dajabón contrae matrimonio con una dominicana, Dominga Arambule (30). Esto significa una radicación en el pleno sentido de la palabra. También Juan Sanchez y Francisco Hinostrosa se asientan, creando allí sus negocios y rompiendo en definitiva todos los lazos con sus familiares peninsulares, muestra de ello es, que en una de las cláusulas del testamento de 
Francisco, donde se nombran a los herederos, éste declara no saber si sus padres y hermanos viven.

En los casos de Thomas Figueras y Pedro Vazquez, no se puede hablar de emigración, ya que ambos dejan a sus esposas e hijos en la península, por lo tanto sus viajes a la isla durarían el tiempo que se tardase en hacer el negocio para el que habían ido. De Joaquin Arizo, sabemos por los datos extraídos de una carta que le envía su padre desde Cádiz, que tenía en su pensamiento la idea de volver, pero la muerte le sorprende muy joven.

A pesar de todo, tanto los que se asentaron para siempre en aquellas tierras, como los que lo hicieron temporalmente, nunca olvidaron sus tierras de origen, de ahí que sus últimos pensamientos siempre estuvieron en la tierra que les vió nacer. Muestra de ello, son algunas de las mandas que se dejan en las disposiciones testamentarias, como misas por el alma, limosnas para la construcción de conventos,etc...todo para llevarse a cabo en la península.

Hemos considerado una serie de parámetros como son cargos $u$ ocupaciones que ejercieron, datos de las familias a las que pertenecieron -como por ejemplo, el oficio de los padres- si sabían leer y escribir -porque aparezca algún documento-, bienes que dejan tras su fallecimiento, etc...para poder establecer el nivel social al que pertenecieron. Adoptando estos baremos, y en relación con otros estudios que hemos hecho para el S.XVI,XVII y XVIII de gaditanos que fallecieron en las Antillas, podemos afirmar que estos indivíduos que ahora presentamos, son hombres que en general pertenecen a un nivel social medio. Por supuesto, hay excepciones, Thomas Figueras perteneció a una familia muy humilde, no sabía leer ni escribir, y los bienes que logra reunir a lo largo de su vida, sumaron escasamente 61 pesos de 128 cuartos, 2 reales de plata y 32 maravedíes; en contraposición está Pedro Vazquez, que poseía propiedades en el típico barrio gaditano de la Viña, que aportó al matrimonio un capital de 1500 pesos, y que tras su muerte dejó un capital de 2175 pesos de 128 cuartos y 29 maravedíes de plata.

En relación al nivel económico, podemos afirmar que en los casos estudiados, éste no difiere del nivel social.

Es complicado llegar a profundizar en las causas que provocaron la muerte a nuestros hombres. Algunos datos que hacen referencia a las enfermedades que padecieron, accidentes, etc,...podemos encontrarlos, en los testamentos.

Si los hombres enfermaban y la situación se agravaba, dependiendo de las posibilidades económicas del indivíduo, bien se le ingresaba en un hospital que normalmente era gratuito (31) o eran asistidos en casas propias o en las de amigos o familiares. Este es el caso de Joaquin Arizo, que pasa toda su larga enfermedad en casa de Joseph Aponte, el Administrador de Fronteras, a quién servía como escribiente; o de Francisco Hinostrosa que enferma y es cuidado por su amigo y albacea Manuel Romero. 
Los gastos de enfermedad no solían ser elevados, así por ejemplo, Pedro Vazquez se gastó 10 pesos en botica, y Joaquin Arizo 4 pesos en una botella de específico para lombrices.

A través, de las cláusulas espirituales, de los que hicieron testamento o memoria testamentaria, hemos podido analizar todo lo relacionado con la religiosidad de estos individuos, las disposiciones hechas respecto a las honras fúnebres, número de misas, mandas pías, fundaciones de capellanías, etc...

Para la mayor parte de estos hombres, tras la muerte, no acababa la esperanza, la fé les hacía confiar en la existencia de un mundo mejor del que iban a abandonar. Por ello, en los testamentos se hace mucho hincapié en las honras fúnebres, mortajas, misas de requiém, sepulturas además de otras misas por sus almas y demás legados piadosos para ganar la gloria.

El hábito que es escogido como mortaja por Joseph Guerrero es el de la Orden de la Merced. Desde la conquista, la devoción ferviente a María se extendió por todo el continente, destacando en Santo Domingo la advocación a la Virgen de la Merced, que es constantemente invocada por estos hombres. Esta devoción a la Virgen, en su advocación de la Merced, hizo que fuera elegida Patrona de la isla en 1614, por los muchos milagros que realizó (32). Además, de en Santo Domingo capital, en la Vega tuvo también muchos devotos, pues su culto estaba íntimamente ligado a la fundación de la ciudad (33). Por ello, todos los 24 de septiembre se celebraba una romería al Santo Cerro. También es el convento de Nuestra Señora de la Merced, el elegido por Joseph Guerrero y Pedro Vazquez para que sus cuerpos sean sepultados, y se digan las misas por sus almas. Diez son las que pide Joseph y cincuenta Pedro. Para la construcción del convento de Nuestra Señora de la Merced de la Villa de Azua, Melchora Barrado -suegra del albacea de Francisco Hinostrosa- deja en su testamento otorgados 25 pesos.

Junto a Nuestra Señora de las Merced, como Patrona Nacional, la otra advocación Mariana que entre nuestros hombres goza de gran devoción, es la Virgen de Altagracia (34), la que se eligió como Protectora Nacional. Su devoción, sobre todo, se centró en Higüey. Francisco Hinostrosa tenía prometido a la Virgen de la Altagracia «una ahogadera», pero como la muerte le sorprende, en su testamento manda que se valore esta alhaja y el valor se le entregue al Mayordomo de la Virgen. Otra muestra de esta devoción es la de Melchora Barrado, la cual como declara en su testamento, prometió visitarla en Higüey y cantarle una misa. Al enfermar y no poder cumplir su promesa, ordenó a su albacea «le consulte a una persona prudente para que la conmute por dinero y se le mande para su culto». Además de ofrecerle cien misas rezadas por la salvación de su alma a cinco reales cada una, otra le brinda a la Santísima Relíquia de la Cruz de la Vega que se venera en la Catedral y al Santísimo Cristo de San Andrés. 
También aparecen en los testamentos, otras disposiciones: las misas de Requiém -o de cuerpo presente-, para que se dijesen el «mismo día de la defunción si fuese hora y si no al día siguiente»; el ofrecimiento de cierta cantidad como limosna para lo que se conoció como «mandas pías forzozas»; y la fundación de capellanías. Joseph Guerrero, en su memoria testamentaria, manda imponer una capellanía de misas rezadas por su alma y la de su mujer. Sería servida por un sobrino-nieto, y en caso de faltar éste, pasaría a la mitra arzobispal dominicana. Al ser el sobrino menor de edad, se nombra mientras tanto a un sacerdote interino. Cuando a los siete años de fallecer Joseph muere su esposa, en su testamento ordena que se una al capital con que dotó su marido la capellanía el dinero que se sacase de la subasta de una casa, que también le legó. También Melchora Barrado funda una capellanía con un tributo de 2000 pesos para que la sirviera Don Francisco del Campo como cura y como patrono Jossef Nolasco, en la Villa de Banica.

EXPEDIENTE DE BIENES DE DIFUNTOS DE GADITANOS FALLECIDOS EN SANTO DOMINGO. S.XVIII. PROCEDENTE DE LA SECCION DE CONTRATACION DEL ARCHIVO GENERAL DE INDIAS DE SEVILLA.

-Año 1750. Auto de los Bienes de Thomas Figueras. Legajo 5609.

-Año 1752. Auto de los Bienes de Juan Sanchez. Legajo 5617.

-Año 1754. Auto de los Bienes de Pedro Vazquez. Legajo 5623.

-Año 1757. Auto de los Bienes de Joseph Guerrero. Legajo 5634, $n^{\circ} 3$.

-Año 1777. Auto de los Bienes de Francisco Hinostrosa. Legajo 5679, $\mathrm{n}^{\circ} 10$.

-Año 1787. Auto de los Bienes de Joaquin Arizo. Legajo 5705, nº12.

\section{APENDICE I. INVENTARIO DE LOS BIENES DE PEDRO VAZQUEZ.}

-Nueve aderezos de diamantes de cruz:

.Una grande con siete diamantes grandes y cuatro pequeños, y treinta punticas de diamantes alrededor, los aritos compañeros de la cruz, ocho diamantes grandes, ocho pequeños y dieciseis puntas.

.Una cruz con 26 diamantes grandes y pequeños, los aritos doce pequeños. .Una cruz con un lazo en el botón,con 35 diamantes y doce aritos.

.Las otras seis cruces tienen cada una sus aritos, con los mismos diamantes que la segunda.

-Una joya de diamantes con un corderillo de perlas.

-Una sortija de esmeraldas.

-Un brazalete de diamanticos.

-Cinco anillos de piedra ingar.

-Doce sortijas de Brueto.

-Un tumbagón con 20 puntas de diamantes con sobrepuesto de oro.

-Una joya con punticas de diamantes con 5 punticas de lo mismo, y un cordero de madre de perlas. 
-Siete anillos:

.Uno con nueve punticas de diamantes.

.Uno con doce punticas de diamantes y una esmeralda.

.Cinco de piedras ingle.

-Doce anillos en brutos con el enganche interior de plata y tres pares de salzillos en la misma conformidad.

\section{APENDICE II. INVENTARIO DE LOS BIENES DE FRANCISCO HINOSTROSA.}

-Una cruz enganchada en oro y aritos de piedra.

-Un broche de oro.

-Una hebilla de corbatin.

-Un par de botones de oro.

-Un relicario.

-Una cajita de plata.

- Un par de hebillas de zapatos y otro de calzones de plata.

-Un par de pistolas grabadas en plata.

-Un espadin de plata.

-Veinte botonaduras de piedras.

-Dos piezas de Persia.

-Dos pìezas de Bretaña.

-Ocho piezas de rejilla -tres lisas y cinco labradas-

-Quince pañitos pequeños.

-Un quitasol de seda.

-Quince espejos pequeños.

-Cuatro batas viejas.

-Trece camisas viejas y blancas.

-Ocho pares de calzones blancos.

-Seis pares de medias y calceta,

-Tres chupas blancas y otra negra.

-Una casaca.

-Tres pares de calzones.

-Cinco pares de medias de seda y lona.

-Ocho paqueticos de hilo.

-Una botonadura carmesi engastada en plata.

-Tres pares de tijeras y tres cuchillitas.

-Dos candeleros de metal.

-Un almirez de bronce.

-Una cuchara y tenedor de plata.

- Una sarten de hierro y una cacerola de metal.

-Un baul grande, otro chico y una hamaca de algodon.

-Un negro nombrado Cupidon de 20 años, criollo de Santo Thome.

-Una negrita llamada Dorotea de trece años, casta Congo. 
-Una funda de almohada.

-Un cajoncito con papeles.

-Tres casacas viejas -color cafe,negra y canela-

-Dos chupas.

-Dos libros grandes de piloto y uno chico.

-Dos cartas de piloto.

-Una ballestilla de piloto 5 minuteros.

-Una tetera de loza.

-Dos faltriqueras de mujeres.

-Un saquito con cuatro dedos de añil.

-Cuatro petaquitas con papeles.

-Un botijito.

-Siete camisas rotas.

-Quince pares de calceta.

-Cinco pares de medias.

-Dos pares de calzones.

-Dos chupas.

-Un baston con puño de oro.

-Treinta y ochoo platos blancos.

-Tres platos grandes.

-Una tina grande de hierro.

-Una silla olandesa.

-Un asador.

-Una caja olandesa.

-Un papelon con 300 tachuelas.

-Dos macutos.

-Seis limetas.

-Una damazera vacia.

-Un par de calzones de terciopelo negro.

-Dos camisas.

-Una goleta nombrada «Santa Rosa.»

\section{NOTAS.}

(1) MOYA PONS, Frank, El pasado dominicano. Fundación J.A. Caro Alvarez, Santo Domingo, República Dominicadana, 1986, p. 15.

(2) NARANJO OROVIO, Consuelo, El Caribe colonial, Colección las Américas, Edición Akal, n² 27, p. 7.

(3) En 1756, Francia e Inglaterra vuelven a iniciar las hostilidades (Guerra de los Siete Años).

(4) CESPEDES DEL CASTILLO, Guillermo, La América Hispánica (14921898). Historia de España dirigida por Manuel Tuñón de Lara, tomo VI, editorial Labor, Barcelona, 1983, p. 181. 
(5) GUTIERREZ ALVIZ, Faustino, Los bienes de difuntos en el derecho Indiano, editorial La Gavidia, Sevilla, 1942, p. 7.

(6) GUTIERREZ ALVIZ, F., op. cit.

(7) OTS CAPDEQUT, José María, Estudio de Historia del Derecho Español en las Indias, Bogotá, 1940.

(8) LEYES. Recopilación de las....de los Reinos de Indias. Mandadas a imprimir y a publicar por Su Magestad Católica, el Rey Carlos II. Por Solórzano Pereira. Tomo III. Libro II, Título XXXII.

(9) GUTIERREZ ALVIZ, F., op. cit., pp. 28 y 29.

(10) MALAGON BARCELON, Javier: El Distrito de la Audiencia de Santo Domingo en los s. XV a XIX. Colección Estudio. Universidad Católica Madre y Maestra. Santiago de los Caballeros. República Dominicana, 1977, p. 15.

(11) Ibidem, pp. 15. Cunnigham las presenta como la institución central del sistema colonial español.

(12) GUTIERREZ ALVIZ, F., op. cit., p. 28.

(13) Ibidem, p. 49.

(14) CORTES ALONSO, Vicenta, «Los esclavos domésticos en América», Anuario de Estudios Americanos, tomo XXIV, Escuela de Estudios Hispano Americanos, Sevilla, 1967, p. 968.

(15) ARCHIVO GENERAL DE INDIAS (en adelante A.G.I.), Sección Contratación, legajo 5679, $\mathrm{n}^{\circ} 10$.

(16) ESTEBAN DEIVE, Carlos: La esclavitud del negro en Santo Domingo (1492-1844), Museo del hombre dominicano, República Dominicana, 1980, p. 306: «La posesión de un esclavo doméstico era hasta tal punto un símbolo de status que incluso aquellos blancos que vivían en la pobreza hacían malabarismos económicos para conseguir por lo menos uno. La casa podía carecer de ajuar o tener sólo lo indispensable, pero nunca o casi nunca faltaba en ella el criado negro».

(17) CASSA, Roberto, Historia social y económica de la República Dominicana, tomo I, Santo Domingo D.N., República Dominicana, 1993, p. 129.

(18) Ibidem. 
(19) A.G.I., Contratación, leg. 5679, nº 10.

(20) LEYES, op. cit., ley LVI.

(21) A.G.I., Contratación, leg. 5679, nº 10.

(22) Ibidem.

(23) A.G.I., Contratación, leg. 5705, n 12.

(24) GUTIERREZ ALVIZ, F., op. cit., p. 49.

(25) A.G.I., Contratación, leg. 5705, nº 12.

(26) COMISION MUNICIPAL PARA LA CELEBRACION DEL QUINTO CENTENARIO DEL DESCUBRIMIENTO Y EVANGELIZACION DE AMERICA, Ayuntamiento del Distrito Nacional de Santo Domingo, Santo Domingo, D.N., 1988, p. 59. El entorno de la Plaza Mayor contó siempre con el gran atractivo de sus edificaciones oficiales y particulares. Estaba además dotada de una hermosa fuente de agua, para servicio público, que se abastecía por cañerías de barro que corrían por debajo de la tierra, por la calle de los Plateros o Meriño actual.

(27) CASSA, Roberto, op. cit., pp. 101 y 127. El situado era dinero que España enviaba anualmente a Santo Domingo desde México y durante algún tiempo desde Panamá. Por lo cual, la Española dispuso de una entrada suplementaria de monedas de plata, que hacia finales del s. XVIII se elevaba a unos 350.000 pesos. Se destinó al mantenimiento de la guarnición de la colonia y del aparato burocrático y parte de los gastos de la Iglesia. Fueron muy importantes porque hicieron posible el mantenimiento de ciertos niveles de comercio interno y externos ya que al hacerse en moneda ésta podía circular por la colonia.

(28) A.G.I., Contratación, leg. 5609.

(29) A.G.I., Contratación, leg. 5623.

(30) BARRIENTOS MARQUEZ, $M^{2}$ del Mar, «Dominga Arambule: una dominicana relacionada con Cádiz», VII Encuentro de la Ilustración al Romanticismo, Universidad de Cádiz, Cádiz, 1994, pp. 165 a 174.

(31) PAREDES VERA, $\mathbf{M}^{\star}$ Isabel, «San Nicolás de Bari en la Española, primer hospital de América», Anuario de Estudios Americanos, tomo XXXII, Escuela de Estudios Hispanoamericanos, Sevilla, 1976, p. 948. El hospital de san Nicolás de Bari es el primer centro hospitalario que se crea en el Nuevo Mundo, y que perduró hasta principios de nuestro siglo. 
(32) ARNAIZ, Francisco José, Más luces que sombras. Colección Quinto Centenario. Santo Domingo, República Dominicana, 1989, pp. 212 y 213. «En el convento de Nuestra Señora de las Mercedes de esta ciudad, ha obrado Dios por ella muchos milagros, particularmente en el año 1614 en un gran temblor que hubo en esta ciudad de Santo Domingo. Víspera en la noche de su fiesta de la Natividad experimentaron el divino favor y sucedió algunas maravillas por donde esta ciudad la eligió como Patrona y Abogada...y votaron de hacer la fiesta en el 8 de septiembre de cada año...y la ciudad la saca en procesión». La fiesta fue trasladada posteriormente al 24 de septiembre.

(33) MOYA PONS, Frank, op. cit., p. 76.

(34) ARNAIZ, Francisco J., op. cit., p. 213. 